\title{
THE CV PHONOLOGICAL TREATMENT OF CONSONANTAL GEMINATES IN ARABIC: A NON-LINEAR APPROACH
}

\author{
Dr. Majid Abdulatif Ibrahim, \\ Al-Zaytoonah University of Jordan, \\ Faculty of Arts, \\ Dept. of English
}

\begin{abstract}
"There are certain common types of consonantal sequences which have special names in phonetic literature and some of which function as single units in particular languages. All of the special sequences... are homorganic, that is, they are articulated by the same organs. The first special sequence type... is known as geminate (from the Latin geminare 'to double', geminus 'twin')" Catford (2002:111)
\end{abstract}

\section{INTRODUCTION}

Like vowels, consonants can be looked upon as segments possibly subsumed under the process of lengthening that is usually given a phonological term, i.e. geminate. In Arabic, geminate may either occur wordmedially or word-finally. The 1-sound of the Arabic definite article '?al-' in such a phrase as ?al Jamas 'the sun' is assimilated to the subsequent solar single consonant. Consequently, an assimilated form would be pronounced

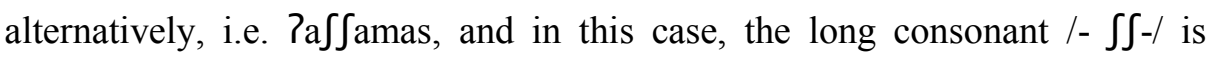
considered a true geminate after eliding / $\mathrm{al}-/$. Word-final geminate does not fulfill a distinctive function in Arabic.

What is worth underlying here is that there are several general characteristics of consonantal geminate that researchers in phonological theory have been investigating for some years, beginning in preautosegmental frameworks and continuing recently within the CV phonological theory. In other words, scholars have attempted to account for these special properties and to see some of the ways as to how geminate behaves phonologically.

The present study is an endeavour to cast light on how The CV model of phonology tackles certain aspects of consonantal geminates in Arabic. Moreover, it concentrates on essential points as to whether geminate consonants are treated as one long segment or ass two short independent exponents that are found at syllable junctions. 


\section{CV PHONOLOGY: THE EVOLUTION OF PHONOLOGICAL NONLINEARITY}

Phonological theory has recently witnessed a substantial change in the nature of its basic orientation. This change has been marked by the development of numerous new theoretical frameworks, which fall within the orbit of nonlinear model of phonology. CV phonology, among these frameworks, comes into being as a result of refining and above all remodeling some of the ingredients, techniques and aspects for which the generative theory of phonology has called.

The CV model presents significant changes in dealing with phonological representations. It is generally viewed as a model which adds a consonant (C) and vowel (V) tier to the syllabic and segment tier (Kahn, 1980; Clements and Keyser, 1983). Once added, the tier will remove the need for the feature [syllabic] at the skeletal tier, and consequently will give rise to the timing slots to be employed melodically. Whenever the CV tier of C and V slots are postulated to be occupied by segments, the segments, these segments can be mapped straightforwardly on to these CV positions, and thus they are to be fully articulated on a phonetic ground. The CV tier is practically seen as an advantageous pattern according to which its own units have the ability to define a certain functional position (i.e. peak vs. non-peak) within the syllable (Clark et al, 2007).

Katamba (1989: 156) argues that the CV theory is required to perform three main tasks: stating universal principles in order to govern syllable structure, stating syllable structure typology and stating language-specific rules to syllable template. On this principle, the syllable is assumed to have three tiered structures that consist of the syllable node, a CV tier and a segmental tier. More importantly, the CV tier is sometimes referred to as the skeleton tier. The rationale behind such an alternative term resides in that it is suggestive of its composition of a string of Cs and Vs, and that it constitutes the baseline of the edifice of sound in language (Roca and Johnson, 1999: 687).

That the timing tier made up of Xs implies that they are units of phonological and abstract timing, and that they are not intended to represent actual measurements. It has been stated that the timing tier is seemingly designed to uncover segment length. A short segment is usually associated with one timing unit, while a long one with two. On the other hand, there are some occasions in which a single timing unit can be associated with two values of a feature, viz. the case of affricates (Carr, 1993: 212). 


\section{GEMINATE: THE UNINTERRUPTED SUCCESSION OF TWO CONSONANTS}

Geminate is seen as an important feature not only in Arabic but also in many languages and dialects. It is lexically defined as the doubling of an originally single consonant or the doubling of a letter in orthography. On the phonetic ground, geminate is accounted for in accordance of two identical articulations and prolongation of the articulatory posture (Catford, 1977; Cruttenden, 2007).

In fact, the line of demarcation between 'long' consonants and geminate ones has been blurred for a long while. Two approaches can be recognized in this connection. In one place, geminate consonants are different from long ones in that the articulation of the former necessitates double phases, i.e. the first phase constitutes a syllable-final occurrence of the consonant, whereas the second phase, which is considered the re-articulated phase, commences the following syllable, and accordingly constitutes a syllable-initial occurrence of the consonant. The other approach treats geminate and long consonants as the same and denies the existence of the two phases (Ladefoged, 2006).

Long and geminate consonants, many other scholars confirm, diverge considerably on the basis that the latter is marked by having articulation extending over two syllables. Accordingly, the term 'double consonants' is sometimes introduced to mean geminate consonants. Abercrombie (1967: 82) states that "a double consonant is one whose duration extends over two syllables, whereas the duration of a long consonant is confined to a single syllable".

In the light of adopting a nonlinear approach of phonology, another classification of consonantal geminate can be made: true geminates and apparent or fake geminates (Goldsmith, 1990; Spencer, 1996). True geminates are multiply associated consonants, but apparent geminates are separately associated consonants acting as a consonant cluster. In other words, this distinction is phonological on the assumption that all geminates, which are internal to a single morpheme, are true geminates and that all geminate formed across a morpheme boundary are only apparent geminates.

\section{GEMINATE CONSONANTS IN ARABIC: ACROSS SYLLABLE BOUNDARY}

When a consonant is geminated in Arabic, it is written once and a small sign called 'shadda' is required to place over the consonant. It is Arab philologists who are credited with the introduction of this sign that is merely an un-looped $\int$-sound derived from the word 'tashdeed' itself. The introduction of the new sign is of a prime importance to avoid confusion with 
corresponding words having single consonants, because the difference between single and geminate consonants has a distinctive function (as seen below).

Treating geminate consonants in Arabic either as one long or two short segment is viewed as a key issue debated time to time. As far as Arabic grammar is concerned, the term geminate is applied to those consonants having a long duration and determined by certain phonetic contexts, or to consonant letters receiving the sign that represents such a long duration (ElSa'aran, 1951:162). The old Arab grammarians consider every geminate consonant as being equivalent to two sounds in pronunciation; the first being saakin 'still' and the second mutaharrik 'moving'. Hence, it is convenient to interpret a geminate consonant in Arabic as being double and not long. This, in turn, paves the way to state that on the ground of syllabification, any intervocalic geminate consonant should be split into two components: one is related to the first syllable and the other to the second syllable (i.e. a geminate consonant is of a single melody element linked to two timing slots). Compare:

[1] Medial single consonants

(a) /nasaba/ 'he constructed'

(b) /amaha/ 'he saw'
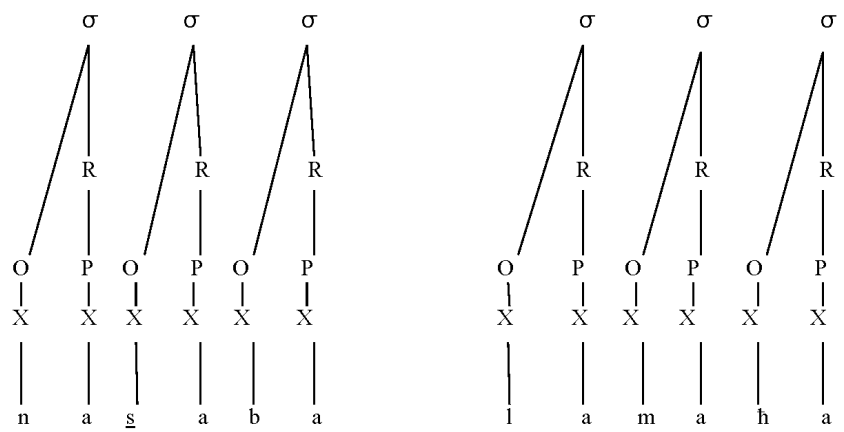

[2] Medial geminate consonants

(a) /nassaba/ 'he appointed'

(b) /ammaha/ 'he hinted at'
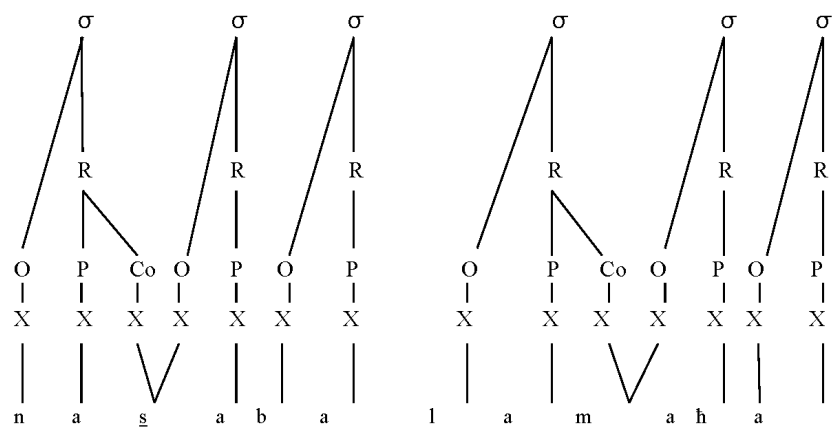
In spite of accepting the definition of a geminate consonant as expressed by the old Arab grammarians and in terms of its syllabic template, i.e. having a CCV pattern, in which the first C-element is a 'still' sound and the other is a 'moving' sound, a geminate in word-initially position becomes an out of question pattern in Arabic. A geminate consonant in Arabic can then only occur either word-medially or word-finally. The V-element can be any of three short vowels $/ \mathrm{i} /, / \mathrm{a} /$ or $/ \mathrm{u} /$ as in $[3 \mathrm{a}],[3 \mathrm{~b}]$ and $[3 \mathrm{c}]$ :

/kajjisun/ 'courteous'

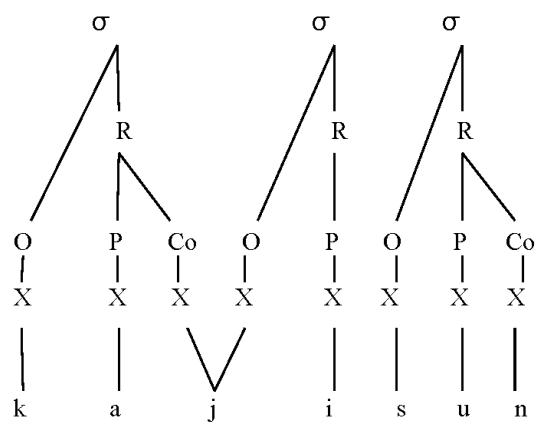

[3b]

/sabbaba/ 'he caused'

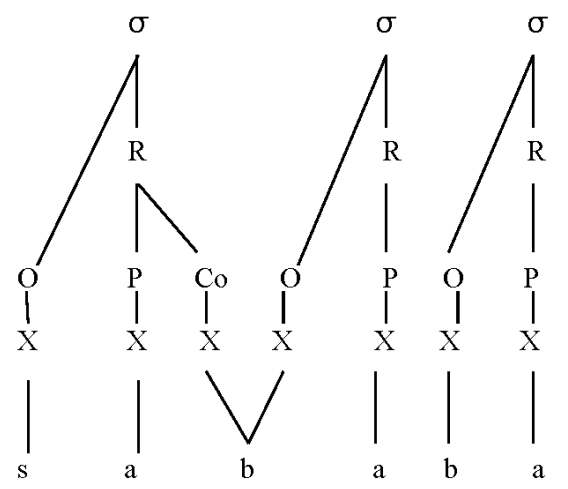

[3c] /tafahhumun/ 'understanding'

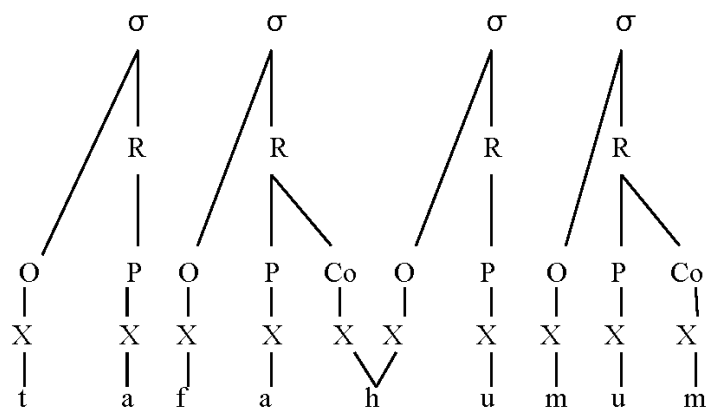


It can also be any of the long vowels /ii/, /aa/ or /uu/ as in [4a], [4b] and $[4 \mathrm{c}]$ :

[4a]

/sikkiinun/ 'a knife'

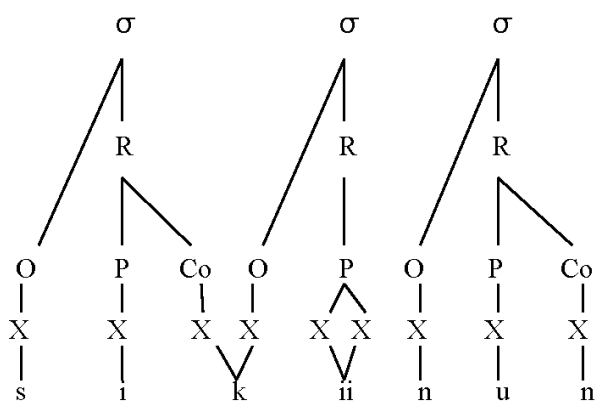

[4b]

/tullaabun/ 'students'

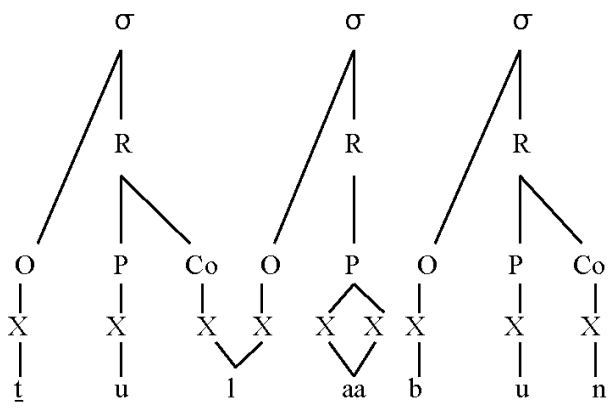

$[4 c]$ /mudzidduuna/ 'hardworkers'

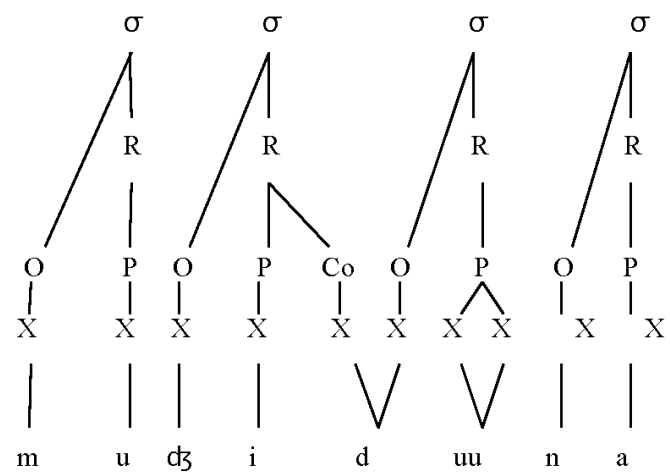

In word-final position, geminate consonants are impossible when the word takes a paused form in which the geminate $(\mathrm{CCV})$ pattern with two timing 
slots crossing two syllables is reduced to a long (c) with two timing slots of a single syllable as indicated in the following two schemas:

[5]

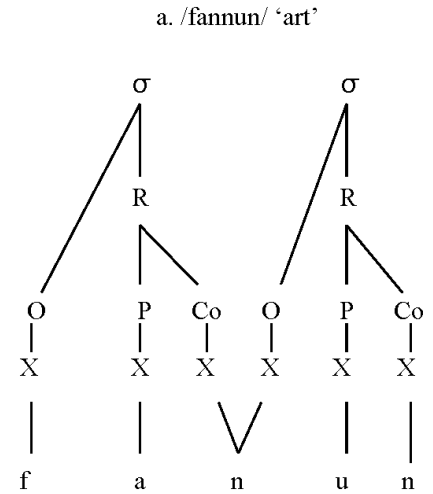

b. /fann/ 'art'

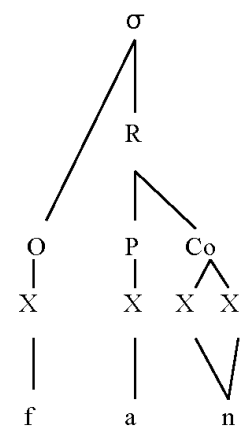

Nevertheless, geminate consonants occurring word-finally do not fulfill distinctive function in Arabic since contrast between single and geminate consonants in this position are out of interest. Articulating a final consonant entails a conscious effort to make it perceptible. That is, a final geminate in Arabic is characterized by tenseness of articulation as compared with a nongeminate partner. As contended by Cowell (1964) and Johnstone (1967), any geminate consonant may finally occur after an accented vowel. At the end of a phrase, however, geminate consonants do not actually contrast with single ones; pronouncing, or even writing, them simply serves to show the position of the accent and their potential significant length before vowels.

\section{GEMINATE CONSONANTS IN ARABIC: A MORPHOLOGICAL SCENE}

Under certain phonetic circumstances, geminate seems to be a basic component of the internal structure of the word. It plays the role of a key factor in deciding on the syllable templates of words. In Arabic, words of medial geminate consonants are significantly divergent from those of corresponding single consonants. There are pairs of words that are distinguished on the basis that one contains word-medial geminate consonant and the other contains its single counterpart. However, this does not necessarily mean that every word in Arabic with a geminate consonant has a corresponding word with a single consonant. Tri-syllabic verbs having the morphological pattern of (fa Sala) for single and (faŞala) for geminate can be cited as examples in this connection: 
[6a] /kasara/ 'he broke'

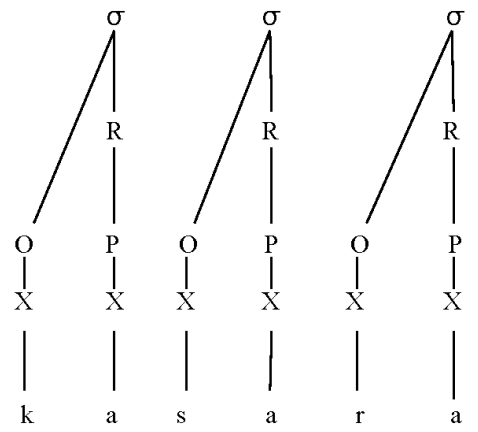

[6b] /kassara/ 'he smashed'

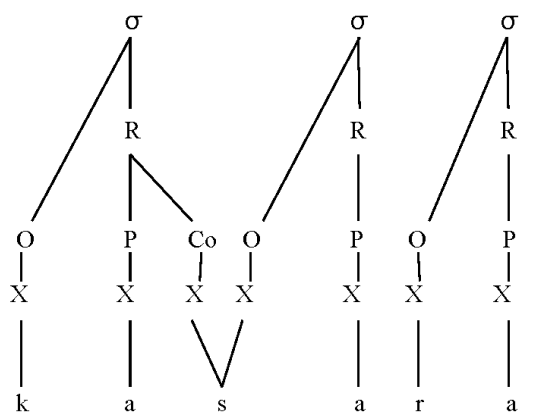

Contrast between single and geminate consonants can also be found in nouns and adjectives, particularly those of the morphological patterns (fa faal) and (fa Şaal):

[7a]

/qasaasuun/ 'punishment'
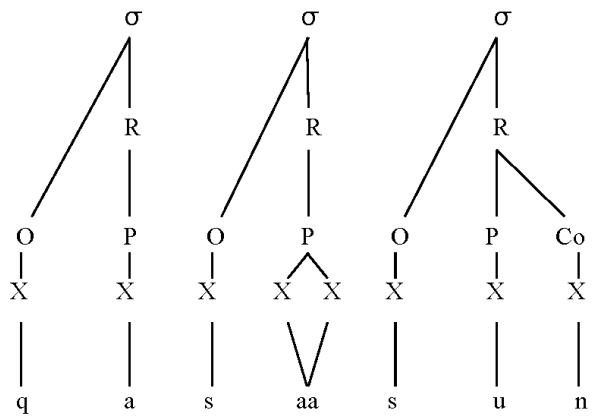
[7b] /qassasun/ 'novelist'

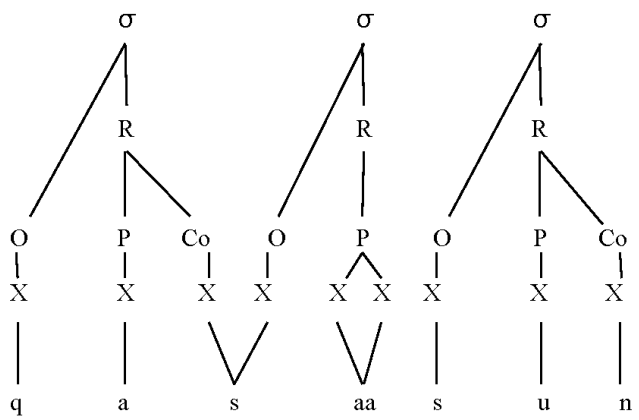

Nevertheless, there are words in Arabic that comprises medial geminates for which no corresponding words with medial single consonants are available. Meanwhile, words of medial; single consonants for which there are no corresponding words of medial geminates are too many to be numerated in Arabic.

Importantly enough, the way a geminate behaves in a derivative situation is one of outstanding feature of geminate consonants in Arabic. Arabic derivations have a vowel inserted between the components of a geminate consonant. This context can be obviously indicated when forming plurals, and while in the singular form the geminate is retained, in the plural form it is separated by inserting a vowel, often /a/, between its components. A singular word such as /Sillatun/ 'cause' is compared with a plural cognate, i.e. /Silalun/ 'causes':

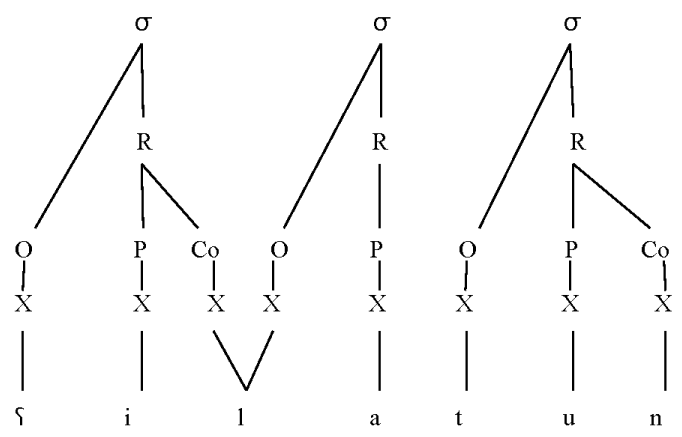

In other contexts, such a situation may take place in reverse. That is to say, the plural form takes the geminate consonant and the singular one perpetuates its single counterpart. Moreover, other changes in the preceding and/or following vowels and the location of stress can be recognized between 
$[8 \mathrm{~b}]$ Silalun/

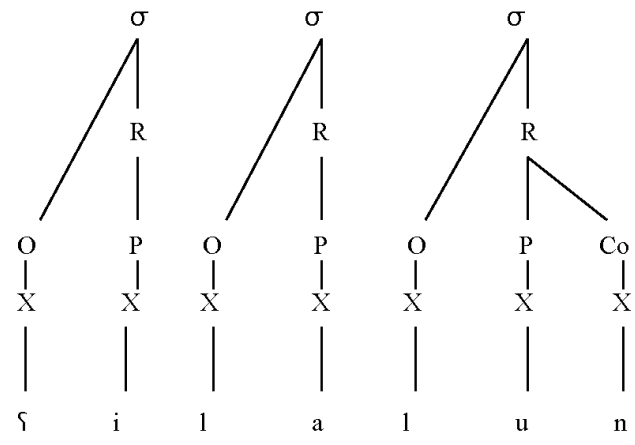

the words in its singular for and that in its plural form, as in shown in the following diagrams:

[9a] hilaalun/ 'crescent'

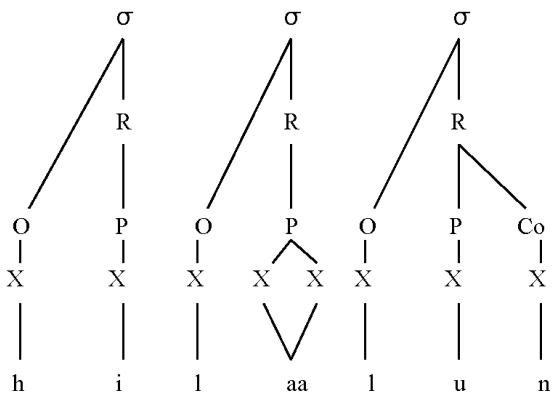

[9b] /Rahillatun/ 'crescents'

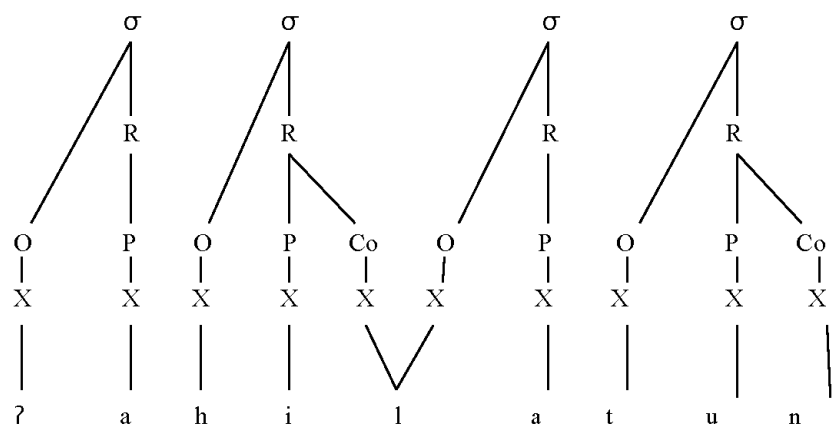

However, in some occasions the geminate consonant may be uttered in singular form as well as in the plural one. 


\section{CONCLUSION}

It becomes apparent that a study as such unveils some sort of findings hopefully utilized to build up a picture of how consonantal geminates in Arabic are tackled from a non-linear angle. In one place, a distinction is made between single and geminate consonants, particularly when they occur wordmedially. Intervocalic geminates are viewed as double and not long segments whereby they are separated into two parts: one belongs to the first syllable and the other to the second syllable. On the other hand, word-final geminates are considered long indivisible entities on the ground that they occur within one and the same syllable template.

\section{REFERENCES}

Abercrombie, D. (1967) Elements of General phonetics. Edinburgh: Edinburgh University Press.

Carr, P. (1993) Phonology. London: Macmillan.

Catford, J. C. (1977) Fundamental Problems in Phonetics. Edinburgh: Edinburgh University Press.

Catford, J. C. (2002) A Practical Course in Phonetics. Oxford: Oxford University Press.

Clark et al. (2007) An Introduction to Phonetics and Phonology. Oxford: Oxford University Press.

Clements, G. N. and Keyser, S. J. (1983) CV Phonology: A Generative Theory of the Syllable. Cambridge, MA: MIT Press.

Cowell, M. (1964) A Reference Grammar of Syrian Arabic. Washington: Georgetown University Press.

El-Saaran, M. H. A. (1951) A Critical Study of the Phonetic Observation of the Arab Grammarians. Unpublished Ph. D Thesis, University of London.

Goldsmith, J. A. (1990) Autosegmental and Metrical Phonology. Oxford: Blackwell.

Cruttenden, A. (2007) Gimson's Pronunciation of English. London: Arnold.

Johnstone, T. M. J. (1967) Eastern Arabian Dialect Studies. Oxford: Oxford University Press.

Kahn, D. (1980) Syllable-based generalizations in English Phonology. New York: Garland.

Katamba, F. (1989) An Introduction to Phonology. London: Longman.

Ladefoged, P. (2006) A Course in Phonetics. Boston: Thomson Wadsworth.

Roca, I. and W. Johnson (1999) A Course in Phonology. Oxford: Blackwell.

Spencer, A. (1996) Phonology: Theory and Description. Oxford: Blackwell. 